\title{
Concentration of Reproduction in Austria: General Trends and Differentials by Educational Attainment and Urban-Rural Setting
}

\author{
Martin Spielauer*
}

\begin{abstract}
In this paper, we explore the inter-individual diversity in fertility among women in Austria for the female birth cohorts 1917-1961. Comparative studies revealed that all Western countries have witnessed a decline in the concentration of reproduction during the $20^{\text {th }}$ century, a trend that has reversed for the most recent cohorts which have reached the end of their reproductive period. This reversal, mainly triggered by an increase in childlessness, has been hardly perceptible in Austria and limited to urban municipalities. Changes in fertility and concentration have followed very different trajectories by educational attainment as well as by the type of municipality in which women lived at age 15 . Within educational categories, we found large differentials by profession and intergenerational educational mobility.

A consequence of the concentration of reproduction is that the level of cohort fertility differs from the average sibship size seen from the children's perspective. In the Austrian case, in contrast to the pronounced fertility differentials by educational attainment, the average sibship size experienced by children became almost independent of parents' education. In contrast to the negative correlation between fertility and concentration found in earlier studies for the first demographic transition and the baby boom, the fertility level and concentration moved in the same direction, and did so for an extended time period following the baby boom, accelerating changes from the children's perspective.
\end{abstract}

\footnotetext{
* Martin Spielauer. Laboratory for Demographic Data, Max Planck Institute for Demographic Research, Konrad-Zuse-Strasse 1, 18057 Rostock, Germany. Email: spielauer@demogr.mpg.de
} 


\section{Introduction}

While increasing specialisation and division of labour are symptomatic of the economic organisation of all modern societies, the opposite applied to long periods of the $20^{\text {th }}$ century concerning population reproduction. Especially the decades around the postwar baby boom were characterised by a decline in interindividual diversity concerning the number of children among women in all Western countries. Childlessness was low and having two children became the general norm. For the more recent decades, a reversal of these trends has been visible in many countries, leading to greater diversity in demographic behaviour, higher childlessness and - especially due to rising childlessness - an increasing concentration of reproduction.

This paper is a descriptive study of trends concerning the concentration of reproduction in Austria for the female birth cohorts 1917-1961. It is mainly inspired by a recent international comparative study by Shkolnikov et al. (2004) on the concentration of reproduction in the 1920-1960 birth cohorts of US and European women (not including Austria) and earlier analyses for Austria by Lutz and Vaupel (1987) and Lutz (1989) covering the first demographic transition and the baby boom. We aim at (1) updating earlier studies on Austria, (2) placing the recent Austrian changes into an international context, and (3) studying concentration trends in different population segments distinguished by educational level, municipality type, profession, and intergenerational educational mobility.

Concentration analysis of human fertility was pioneered by Vaupel and Goodwin (1987) who studied US-women born 1868-1931. They found that the concentration was highest among the 1910 birth cohort and lowest for the youngest cohorts. As shown by Shkolnikov et al. (2004), the trend of decreasing concentration reversed in the US immediately after the baby boom (i.e., for women born after 1932) and - with a delay of up to two decades - in all other western European countries under investigation.

Lutz and Vaupel (1997) looked at the concentration of births in marriage cohorts from the late $18^{\text {th }}$ century to 1924 , based on birth history data of the German-Austrian census (Reichsfamilienstatistik) of 1939, the central period of the first demographic transition in the studied region in which (marital) cohort fertility dropped from 4,7 to 2,3 children. They found an increase in concentration, resulting in a less pronounced fertility transition from the children's perspective: mean sibship size of children decreased less markedly than the average level of fertility - a phenomenon that can be seen as one of the main consequences of reproduction concentration (discussed in Section 3). As shown in Lutz (1989), increasing concentration reflected a pattern of the first demographic transition that was almost universal, as the fertility decline usually did not affect 
all population segments to the same extent and at the same speed. ${ }^{1}$ The negative correlation between the fertility level and concentration can also be found in most cross-sectional comparisons, e.g., between occupational groups (Lutz and Vaupel 1987) and countries (Lutz 1989).

During the baby boom, increasing fertility coincided with decreasing concentration, again leading to less pronounced changes from the children's perspective. As shown in this study, this pattern was inverted after the peak of the baby boom for the birth cohorts 1935-55, i.e., fertility and concentration decreased simultaneously. As a result, the drop of average family size was more pronounced from the children's perspective. At the same time and in spite of considerable fertility differentials by education, the differences in concentration led to a convergence of average sibship sizes of children with mothers of different educational attainments. The recent increase of concentration observed for all Western countries and studied in Shkolnikov et al. (2004) was hardly perceptible in Austria and limited to urban municipalities; like in most countries, it can be entirely attributed to the increase in childlessness. Within educational groups, we find a high variation of concentration by occupation; more detailed analyses on education also reveal a strong impact of educational mobility on concentration: in the lower educational strata, downward mobility leads to much higher levels of concentration (and childlessness); by contrast, concentration (and childlessness) is highest for university graduates whose parents did not obtain tertiary education. As the educational composition of the population in rural municipalities is very different to that of urban ones, we adjust for composition effects and thus find that educational differences of concentration are small between all non-tertiary educational groups.

This paper is organised as follows: Section 2 introduces the concepts and measures of concentration, followed by a general discussion of the importance and consequences of concentration and a description of data sources. In the following part, we analyse the concentration of reproduction in Austria, beginning with an international comparison and followed by a more detailed discussion of the general Austrian trends. The next sections go into more detail, analysing concentration trends by individual characteristics such as educational attainment, rural-urban setting, profession, and intergenerational educational mobility.

A remarkable exception is the fertility decline in China which was not accompanied by an increase of concentration (Lutz 1989). 


\section{Measures of the Concentration of Reproduction}

The concentration ratio or Gini coefficient, widely used in economics and calculated from the Lorenz curve, is the main measure of concentration used in this study. The Lorenz curve displays the cumulative percentage of output (children) born by the cumulative percentage of producers (women) of a given birth cohort. The Gini coefficient is the area between the Lorenz curve and the main diagonal, divided by the total area above the diagonal. This measure has a theoretical range between 0 (each woman has the same number of children) and 1 (all children are born to one woman) and can be interpreted as the average interindividual difference in the number of children relative to the mean number of children.

Alternative measures that can be read directly from the Lorenz curve are the Have-Half and Half-Have measures as proposed by Goodwin and Vaupel (1985). Have-Half refers to the percentage of women who have half of the children $(28 \%$ for the Austrian birth cohort 1957-61, as displayed in Figure 1. The Half-Have measure denotes the percentage of children born by half of the women (around $75 \%$ for the Austrian birth cohort 1957-61).

While all three measures are highly correlated ${ }^{2}$, they do not always rank different distributions in the same order. This applies to Austria for the studied birth cohorts after 1950. For these the Gini coefficient indicates a slight increase of concentration, whereas the Have-Half measure indicates the opposite. Another illustrative example is given in Figure 1, which displays Lorenz curves for two different birth cohorts as well as for the university graduates of the younger cohort. While the latter-mainly due to a much higher level of childlessnessdisplay the largest area below their Lorenz curve (and therefore the highest concentration ratio), their concentration measured as Have-Half falls between the other two distributions.

In our analysis we opted for the Gini coefficient due to its more favourable statistical properties. While this measure might be less intuitive, it nevertheless meets the Pigou-Dalton condition (or transfer principle): any transfer between two individuals that leaves them more equal reduces the value of the index. This condition is not met by "half" statistics. For instance, assume a population of $\mathrm{x}$ women with parity zero (childless) to four and a total number of $2 \mathrm{x}$ children. If half of the children are born to women of parity four, then $25 \%$ of the women have half of the children regardless whether the other children are relatively evenly ${ }^{3}$ distributed among the remaining women or whether $50 \%$ of all women stay childless while also the second half of children is born to women with parity

2 Shkolnikov et al. (2004) found Pearson's correlation coefficients varying from 0.93 to 0.97 for the set of countries that Austria is compared with in Figure 2.

3 Given that $25 \%$ of the women have parity four, the most even distribution in this example is attained if $50 \%$ have one and $25 \%$ have two children. 
four. The Gini coefficient captures these differences in concentration; in the given example it possesses a theoretical range from 0.31 to 0.50 .

Figure 1

Lorenz curve and concentration measures for Austria

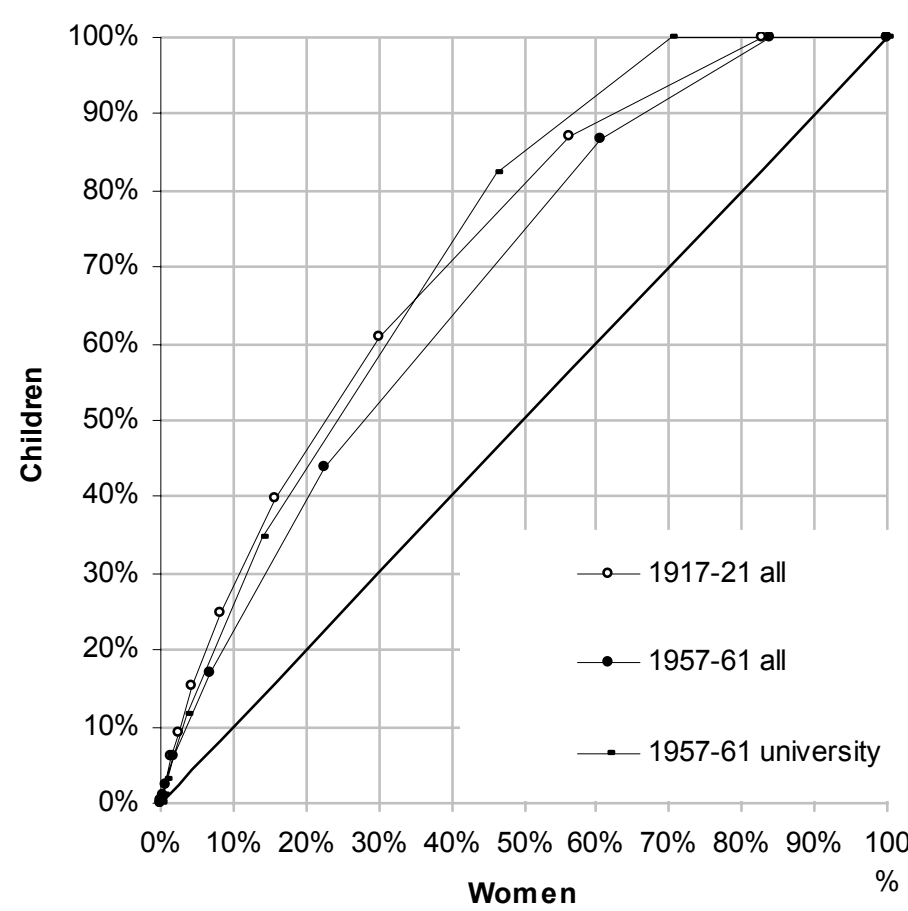

\begin{tabular}{ccc|lcc}
\hline \multicolumn{3}{c|}{$\begin{array}{c}\text { All women by birth cohort } \\
\text { Concentration } \\
\text { ratio }\end{array}$} & Have-half & \multicolumn{3}{|c}{ Attained education } & $\begin{array}{c}\text { Woncentration } \\
\text { ratio }\end{array}$ & Have-half \\
\hline $1917-21$ & 0.44 & $22.8 \%$ & Compulsory & 0.35 & $27.7 \%$ \\
$1922-26$ & 0.45 & $22.4 \%$ & Vocational & 0.34 & $29.6 \%$ \\
$1927-31$ & 0.43 & $23.5 \%$ & Matura & 0.41 & $26.6 \%$ \\
$1932-36$ & 0.39 & $25.1 \%$ & Academy & 0.36 & $28.9 \%$ \\
$1937-41$ & 0.37 & $26.6 \%$ & University & 0.46 & $24.4 \%$ \\
$1942-46$ & 0.36 & $26.9 \%$ & & & \\
$1947-51$ & 0.35 & $27.2 \%$ & & & \\
$1952-56$ & 0.36 & $27.7 \%$ & & & \\
$1957-61$ & 0.36 & $28.0 \%$ & & & \\
\hline
\end{tabular}

Source: Census 2001, own calculations. 


\section{Consequences of the Concentration of Reproduction}

The concentration of reproduction has a number of socio-economic and demographic consequences, many of them discussed in Lutz (1989). One of the main demographic implications of concentration is that the mean family size experienced by children is larger than the average family size of mothers and of women in general. For example, a high concentration of reproduction might imply that a mean family size of two children per women coincides with a mean family size of three children per mother (if $1 / 3^{\text {rd }}$ of women stay childless). This mean family size, in turn, might coincide with a mean of five children when seen from the perspective of an average child (e.g., if $60 \%$ of mothers have one and $40 \%$ have 6 children, then $80 \%$ of the children live in families with 6 children and $20 \%$ do not have siblings). This difference is an important consequence of concentration: changes in sibship size experienced by children depend both on changes in the level of fertility and on its concentration. Accordingly, fertility differentials between women of different population groups do not imply automatically different average family sizes from the children's perspective, a result that we will find for different educational groups in Austria. Mathematically, the difference between the average number of children per women - the mean parity or cohort fertility - and the average sibship size from the children's perspective is the variance of the parity distribution divided by its mean. Empirically, fertility changes are almost always accompanied by changes in concentration, as they usually do not affect all population segments to the same extent. Thereby, the direction of changes can move in the same or opposite direction, the latter having been an almost universal experience during the first demographic transition and the baby boom.

According to the positive effect of concentration on the average family size from the children's perspective, concentration, for any given level of fertility, alters the socialisation environment of children if sibship size is seen as an important factor in this respect. Especially childhood experiences of only children are generally assumed to be different from that of children with siblings, even though the consequences of these differences are ambiguous (Nave-Herz 2002). Differences in socialisation might also impact on the fertility level of the next generation: if the family size of mothers is correlated with the family size of daughters - there exists empirical evidence for a small but positive correlation (Murphy 1999) - a high concentration will positively impact on future fertility.

The influence of concentration on kinship networks is another demographic effect. For any given level of fertility, concentration alters the distribution of the number and existence of kin both horizontally-brothers and sisters-and vertically - children. Due to the high importance of relatives as providers of care, concentration therefore influences the availability of kin for informal care and the organisation of care systems in general. Especially high levels of childlessness can be expected to increase the demand of formal care services. 
An interesting aspect of concentration is a possible link to gender inequality: assuming that family size influences the division of labour between parents, for a given level of fertility higher concentration will be associated with a higher prevalence of traditional patterns. Family policies might impact on the concentration of reproduction by setting different priorities between cash compensation for raising children and the provision of institutional childcare together with the promotion of female labour market opportunities (e.g., Spielauer 2004b), even if their impact on fertility levels is rather ambiguous.

Raising children involves huge costs in terms of parental money and time, even with family-friendly policies. The concentration of reproduction therefore has implications on how - and how equal - this burden is shared in a society. Concentration generates socioeconomic inequalities by family size: household incomes have to be divided by different numbers of family members while family obligations negatively impact on work career potentials. Concentration therefore also impacts on the structure of economic demand. For instance, a high percentage of childless couples ("DINK's" - double income no kids) will increase the demand for certain (luxury) goods; larger families will require larger housing units and might prefer suburban or rural settings while their purchasing power is comparably low.

\section{Data Sources and Limitations}

This type of analysis requires cohort data on parity distributions. Earlier studies on Austria, which due to data restrictions in part only include marital fertility (Lutz and Vaupel 1987, Lutz 1989), were mainly based on marriage cohorts; in this study, however, and similar to Shkolnikov et al. (2004), we use birth cohorts and include all women in our analysis.

Generally, parity distributions by birth cohort can be obtained from two types of data sources. A source frequently used in international comparisons (e.g., Frejka et al. 2001, Shkolnikov et al., 2004) are register data that allow us to calculate parity progression rates from age and parity-specific fertility rates. In order to calculate parity progression rates it is essential that the vital statistics registration of births record births by parity and age of the mother. However, this method of registration has been used in Austria only since 1984. As Austrian register data do not allow constructing time series for earlier birth cohorts, this data source will not be used further in this study.

Census data and sample survey data are alternative data sources, provided that they include information on parity. Data sources for Austria include the 2001 population census and the special programs of the 1996 and 2001 micro- 
censuses. ${ }^{4}$ Estimations based on these data might be biased due to differential mortality and migration, besides the common problems of surveys, e.g., nonresponse. The bias can be expected to be highest for the oldest birth cohorts, for which the descriptive results should be interpreted with some caution. Parity progression rates based on census data were published by Hanika (2003); census data used in this study stem from the online database of the Austrian Statistical Office ${ }^{5}$, which allows tabulating the female population of 2001 by 5 -year age cohorts ${ }^{6}$, parity, and education level.

Single-year cohort fertility and parity distribution rates (up to parity $4+$ ) for Austria that combine estimates based on censuses with estimates based on vital registration are published in the New Cronos Database of Eurostat. ${ }^{7}$ Compared to these data, cohort fertility is slightly higher in census and microcensus data; given the comparably large changes over time, we believe that this difference can be ignored when studying concentration. A comparison of results with earlier studies is possible for the birth cohorts 1921-1945, which were analysed by Lutz and Vaupel (1987) and Lutz (1989) based on microcensus data from 1981. We found considerable differences between the calculations based on these earlier data and the data sources used in our study which cannot be entirely explained by the fact that Lutz and Vaupel only included births up to age 35 in their analysis (see Table $1)$.

In addition to the census data, the special module of the 1996 microcensus contains information on the place and municipality type of residence at age 15, profession and parental education, all of which was used in this study. The sample size of women born between 1917 and 1956 that participated in the special program of the microcensus is 13,200 .

4 Unlike the 1996 microcensus, the 2001 microcensus does not contain information on the place and municipality type of residence at age 15 . For this reason, it was only used in the analysis of education-profession interaction (Figure 8).

5 http://www.statistik.at, http://www.statistik.at/isis/current/isis_gui.shtml

6 As the 2001 census data are published for five-year age cohorts, a conversion to birth cohorts leads to cohorts 1917-21, 1922-26 etc. For reasons of comparison, we use the same cohort limits when building 5-year cohorts from other data sources.

7 http://europa.eu.int/comm/eurostat/newcronos/ 
Table 1:

Cohort fertility, concentration ratios, and have-half measures in different data sources

\begin{tabular}{|c|c|c|c|c|c|c|c|c|c|c|}
\hline \multirow[b]{2}{*}{$\begin{array}{l}\text { Birth } \\
\text { cohort }\end{array}$} & \multirow{2}{*}{$\begin{array}{c}\text { New } \\
\text { Cronos } \\
\text { Cohort } \\
\text { fertility }\end{array}$} & \multicolumn{3}{|c|}{ Census 2001} & \multicolumn{3}{|c|}{ Microcensus 1996} & \multicolumn{3}{|c|}{$\begin{array}{l}\text { Microcensus 1981 } \\
\text { (Lutz 1989) }\end{array}$} \\
\hline & & $\begin{array}{l}\text { Cohort } \\
\text { fertility }\end{array}$ & $\begin{array}{l}\text { Have- } \\
\text { half }\end{array}$ & $\begin{array}{l}\text { CR } \\
\text { (Gini) }\end{array}$ & $\begin{array}{l}\text { Cohort } \\
\text { fertility }\end{array}$ & $\begin{array}{l}\text { Have } \\
\text {-half }\end{array}$ & $\begin{array}{l}\text { CR } \\
\text { (Gini) }\end{array}$ & $\begin{array}{l}\text { CF up } \\
\text { to } 35\end{array}$ & $\begin{array}{l}\text { Have- } \\
\text { half }\end{array}$ & $\begin{array}{l}\text { Birth } \\
\text { cohort }\end{array}$ \\
\hline $1917-21$ & -- & 2.02 & 0.23 & 0.44 & 2.08 & 0.23 & 0.44 & - & - & - \\
\hline $1922-26$ & -- & 2.05 & 0.22 & 0.45 & 2.04 & 0.22 & 0.45 & 1.65 & 0.21 & $1921-25$ \\
\hline $1927-31$ & 2.30 & 2.24 & 0.23 & 0.43 & 2.28 & 0.24 & 0.42 & 1.82 & 0.23 & $1926-30$ \\
\hline $1932-36$ & 2.44 & 2.45 & 0.25 & 0.39 & 2.42 & 0.25 & 0.39 & 2.01 & 0.26 & $1931-35$ \\
\hline $1937-41$ & 2.23 & 2.31 & 0.27 & 0.37 & 2.30 & 0.28 & 0.35 & 2.15 & 0.28 & $1936-40$ \\
\hline $1942-46$ & 1.98 & 2.08 & 0.27 & 0.36 & 2.09 & 0.28 & 0.36 & 2.03 & 0.27 & $1941-45$ \\
\hline $1947-51$ & 1.89 & 1.98 & 0.27 & 0.35 & 1.96 & 0.28 & 0.33 & -- & -- & -- \\
\hline $1952-56$ & 1.78 & 1.86 & 0.28 & 0.36 & 1.85 & 0.29 & 0.34 & -- & -- & -- \\
\hline $1957-61$ & 1.71 & 1.77 & 0.28 & 0.36 & & & & -- & -- & -- \\
\hline
\end{tabular}

Source: Eurostat New Cronos, Census 2001, Microcensus 1996; own calculations; numbers from Microcensus 1981 quoted from Lutz (1989).

\section{Fertility Dynamics and Changes in the Concentration of Reproduction for the Female Age Cohorts 1917-1961}

\subsection{Austrian Trends in the European Context}

With a duration of 65 years, the first demographic transition of Austria (together with the Hungarian one) was among the shortest in Europe. After the mortality decline in the last decades of the $19^{\text {th }}$ century, the natural population increase peaked at 12 per thousand in 1895-1910 (Podrazka 1989), followed by a sharp fertility drop in the following two decades of the $20^{\text {th }}$ century when the crude birth rate decreased from around 30 to 12.8 per thousand in 1938; Austria thus approached the lowest period fertility in the world between the two world wars (Frejka and Sardon 2004).

Austria currently has one of the highest levels of childlessness: according to census data (2001), $16.1 \%$ of the $40-44$ year old and $19.1 \%$ of the $35-39$ year old women have no children. Estimations by Frejka and Sardon (2003) based on register data indicate a proportion of $23.2 \%$ for the 1965 birth cohort. The highest level is currently observed in Germany, with values ranging from $23 \%$ to $26 \%$ in the 1960 birth cohort and 32\% in the 1965 birth cohort according to Kreyenfeld (2002) and BIB (2000). High rates of childlessness are not a new phenomenon in Austria. It was already comparably high (18\%) for the oldest cohorts studied in this paper-women born around 1920; subsequently, childlessness dropped to its lowest point for women born in the mid and late 1930s (12\%), a decrease that 
accompanied the baby boom produced by mothers of the same cohorts. After the boom, fertility declined rapidly, first by a reduction of higher-order parity progression rates followed by an increase in childlessness.

In comparison with other European countries and the US, births are highly concentrated in Austria. Of the 11 countries in Figure 2, only the US displays a higher concentration ratio for the most recent cohorts. Figure 2 also shows that the concentration of reproduction has been decreasing in most countries, with a recent reversal of this trend occurring in almost all of them, a trend produced by increasing proportions of childlessness as shown in Shkolnikov et al. (2004). The same trajectory of concentration can also be found in countries that did not witness a baby boom (Sweden and the eastern European countries); in contrast to this general pattern, the reversal in trend is only very small for Austria. However, we might expect a stronger increase for women born after 1960 due the most recent increase in childlessness.

\section{Figure 2:}

\section{Cohort fertility and concentration ratio by birth cohort in selected countries}

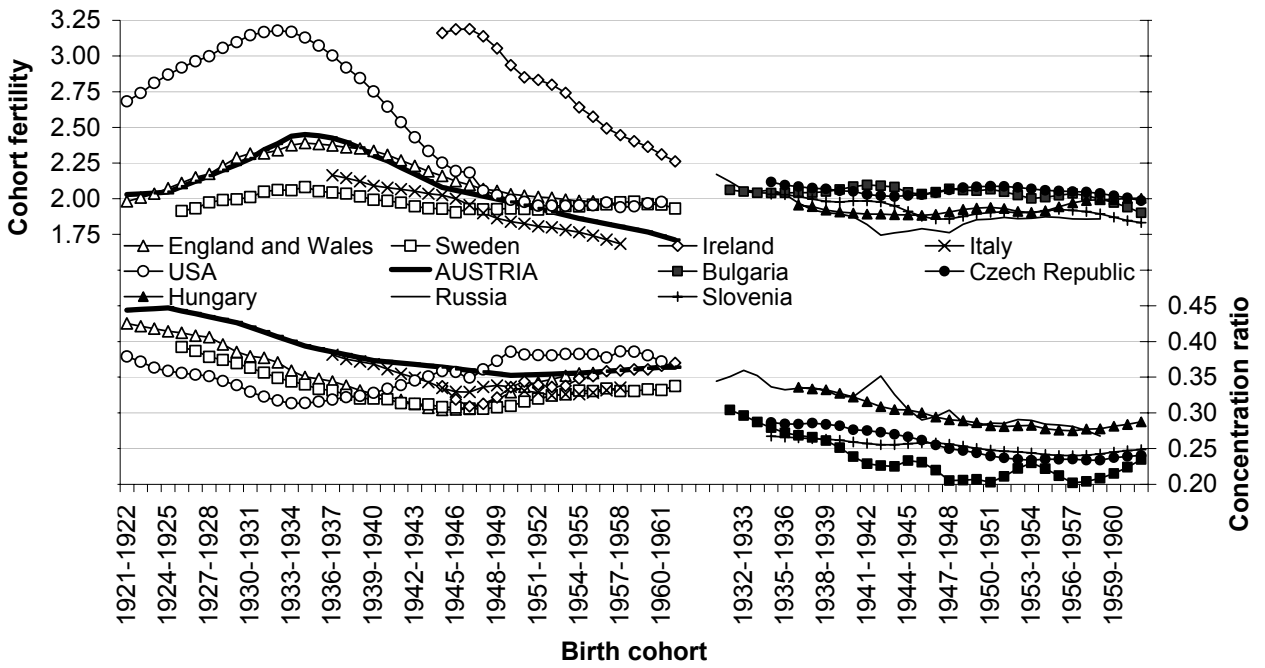

Source: Shkolnikov et al. (2004); Austria: Census 2001, and own calculations.

Table 2 compares fertility and concentration measures for 20 European countries and the US for the birth cohort 1960. Germany displays the highest concentration, but also the lowest cohort fertility. In difference to earlier crosssectional comparisons by Lutz (1989), no general negative correlation can be found between the fertility level and concentration, e.g., the second-lowest fertility of Spain coincides with one of the lowest concentrations in western 
Europe. (The correlation coefficient for Western countries is -0.295 ; that for formerly Socialist countries is stronger and positive: 0.691 ).

Table 2:

Cohort fertility, concentration measures, parity distributions, and the distribution of children by family size for birth cohorts around 1960 in 21 countries

\begin{tabular}{|c|c|c|c|c|c|c|c|c|c|c|c|c|c|}
\hline \multirow[t]{2}{*}{ Country } & \multirow[t]{2}{*}{ Cohort } & \multirow[t]{2}{*}{$C F$} & \multirow[t]{2}{*}{$C R$} & \multirow[t]{2}{*}{$\begin{array}{l}\text { Have } \\
\text {-half }\end{array}$} & \multicolumn{5}{|c|}{$\begin{array}{l}\text { Proportion of women by } \\
\text { number of children }\end{array}$} & \multicolumn{4}{|c|}{$\begin{array}{l}\text { Proportion of children } \\
\text { by family size }\end{array}$} \\
\hline & & & & & 0 & 1 & 2 & 3 & $4+$ & 1 & 2 & 3 & $4+$ \\
\hline West Germany (1) & 1960 & 1.48 & 0.43 & $26 \%$ & $24 \%$ & $27 \%$ & $34 \%$ & $10 \%$ & $5 \%$ & $18 \%$ & $46 \%$ & $20 \%$ & $16 \%$ \\
\hline Finland (4) & $1961-62$ & 1.89 & 0.38 & $27 \%$ & $19 \%$ & $16 \%$ & $36 \%$ & $20 \%$ & $9 \%$ & $8 \%$ & $38 \%$ & $32 \%$ & $22 \%$ \\
\hline USA (5) & $1960-61$ & 1.98 & 0.37 & $27 \%$ & $16 \%$ & $19 \%$ & $35 \%$ & $19 \%$ & $11 \%$ & $10 \%$ & $35 \%$ & $29 \%$ & $27 \%$ \\
\hline Ireland (4) & $1961-62$ & 2.26 & 0.37 & $28 \%$ & $18 \%$ & $10 \%$ & $29 \%$ & $24 \%$ & $18 \%$ & $5 \%$ & $26 \%$ & $32 \%$ & $37 \%$ \\
\hline Austria (7) & $1957-61$ & 1.77 & 0.36 & $28 \%$ & $16 \%$ & $23 \%$ & $38 \%$ & $16 \%$ & $7 \%$ & $13 \%$ & $43 \%$ & $27 \%$ & $17 \%$ \\
\hline Netherlands (2) & 1960 & 1.82 & 0.36 & $28 \%$ & $19 \%$ & $16 \%$ & $41 \%$ & $18 \%$ & $7 \%$ & $9 \%$ & $45 \%$ & $30 \%$ & $17 \%$ \\
\hline $\begin{array}{l}\text { England and Wales } \\
\text { (4) }\end{array}$ & $1955-56$ & 1.98 & 0.36 & $28 \%$ & $18 \%$ & $13 \%$ & $39 \%$ & $21 \%$ & $10 \%$ & $6 \%$ & $40 \%$ & $31 \%$ & $23 \%$ \\
\hline Sweden (2) & 1962 & 1.92 & 0.35 & $28 \%$ & $16 \%$ & $17 \%$ & $40 \%$ & $18 \%$ & $9 \%$ & $9 \%$ & $42 \%$ & $29 \%$ & $21 \%$ \\
\hline Italy (4) & $1957-58$ & 1.69 & 0.34 & $31 \%$ & $15 \%$ & $25 \%$ & $42 \%$ & $14 \%$ & $4 \%$ & $15 \%$ & $50 \%$ & $24 \%$ & $10 \%$ \\
\hline Romania (4) & $1960-61$ & 2.07 & 0.33 & $27 \%$ & $9 \%$ & $24 \%$ & $39 \%$ & $14 \%$ & $14 \%$ & $12 \%$ & $38 \%$ & $20 \%$ & $30 \%$ \\
\hline France (3) & 1960 & 2.10 & 0.31 & $30 \%$ & $10 \%$ & $18 \%$ & $40 \%$ & $20 \%$ & $10 \%$ & $9 \%$ & $38 \%$ & $32 \%$ & $22 \%$ \\
\hline Denmark (4) & $1956-57$ & 1.84 & 0.31 & $32 \%$ & $13 \%$ & $19 \%$ & $46 \%$ & $17 \%$ & $5 \%$ & $11 \%$ & $50 \%$ & $28 \%$ & $12 \%$ \\
\hline Spain (4) & $1960-61$ & 1.70 & 0.30 & $33 \%$ & $12 \%$ & $26 \%$ & $47 \%$ & $12 \%$ & $3 \%$ & $16 \%$ & $55 \%$ & $21 \%$ & $9 \%$ \\
\hline Norway (2) & 1960 & 2.09 & 0.30 & $31 \%$ & $11 \%$ & $15 \%$ & $41 \%$ & $26 \%$ & $7 \%$ & $7 \%$ & $39 \%$ & $38 \%$ & $16 \%$ \\
\hline Slovakia (4) & $1961-62$ & 2.14 & 0.29 & $30 \%$ & $10 \%$ & $14 \%$ & $46 \%$ & $21 \%$ & $10 \%$ & $6 \%$ & $43 \%$ & $29 \%$ & $22 \%$ \\
\hline Hungary (4) & $1961-62$ & 2.01 & 0.29 & $32 \%$ & $8 \%$ & $21 \%$ & $48 \%$ & $17 \%$ & $7 \%$ & $10 \%$ & $48 \%$ & $25 \%$ & $17 \%$ \\
\hline Greece (4) & $1959-60$ & 1.90 & 0.28 & $33 \%$ & $12 \%$ & $16 \%$ & $52 \%$ & $16 \%$ & $5 \%$ & $8 \%$ & $55 \%$ & $25 \%$ & $13 \%$ \\
\hline Russia (6) & $1958-59$ & 1.86 & 0.27 & $34 \%$ & $6 \%$ & $27 \%$ & $50 \%$ & $13 \%$ & $5 \%$ & $14 \%$ & $53 \%$ & $21 \%$ & $12 \%$ \\
\hline Slovenia (4) & $1961-62$ & 1.83 & 0.24 & $36 \%$ & $6 \%$ & $25 \%$ & $53 \%$ & $13 \%$ & $3 \%$ & $14 \%$ & $58 \%$ & $22 \%$ & $7 \%$ \\
\hline Czech Republic (4) & $1961-62$ & 1.99 & 0.24 & $35 \%$ & $7 \%$ & $16 \%$ & $55 \%$ & $17 \%$ & $5 \%$ & $8 \%$ & $56 \%$ & $25 \%$ & $11 \%$ \\
\hline Bulgaria (4) & $1962-63$ & 1.88 & 0.24 & $36 \%$ & $5 \%$ & $24 \%$ & $57 \%$ & $10 \%$ & $4 \%$ & $13 \%$ & $61 \%$ & $16 \%$ & $11 \%$ \\
\hline
\end{tabular}

Sources: Shkolnikov et. al. 2004; Own calculations (Austria)

(1) Calculations from data by Kreyenfeld (2002). Estimates for West Germany correspond to fertility completed by age 35 .

(2) Calculations from the Eurostat/New Cronos (2002) database.

(3) Calculations from data by Toulemon (2001).

(4) Calculations from the ODE (2003) data collection.

(5) Calculations from data by Heuser (1976) updated by W.Kingkade.

(6) Calculations from Goskomstat's statistical tables.

(7) Calculations from Census Data. 


\subsection{General Fertility and Concentration Trends in Austria and their Decomposition by Municipality Type}

During the last century, fertility peaked at an average of 2.5 children per women of the birth cohort 1932-36. The preceding increase in cohort fertility was mainly triggered by raising lower-order parity progression rates, i.e., a reduction in childlessness and higher parity progressions to second births. After the baby boom, the decrease of cohort fertility was initially driven by a fast reduction of higher-order births and, more recently, by increasing levels of childlessness. As displayed in Figure 3, this led to a period of 15-20 years during which fertility and concentration decreased simultaneously. This is a new phenomenon that is in

Figure 3:

Cohort fertility, average family size, and proportion of only children from a children's perspective, and concentration measures

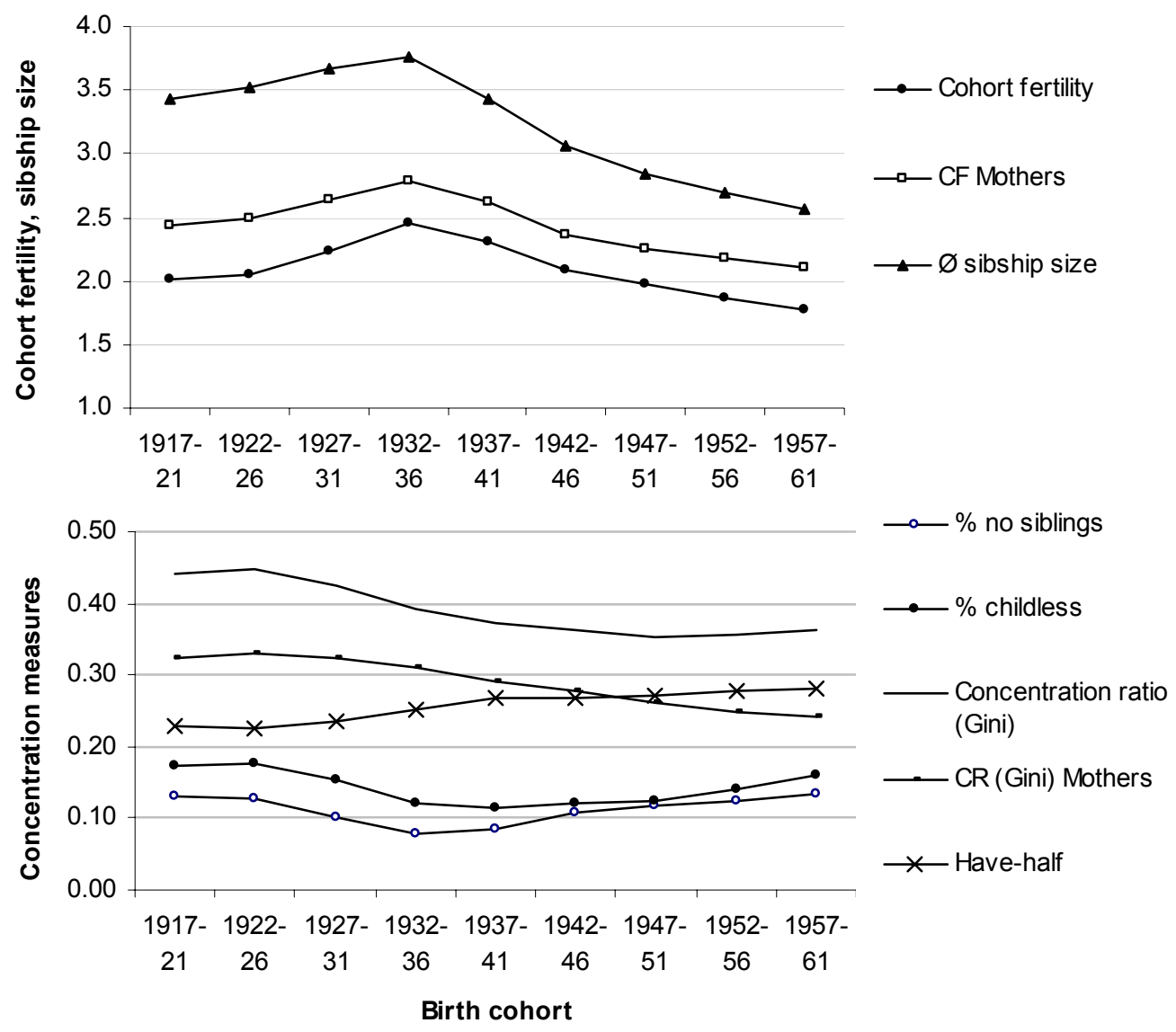

Source: Census 2001; own calculations. 
contrast to the former negative correlation of both trends found in earlier studies covering the baby boom and the first demographic transition in Austria (Lutz and Vaupel 1987, Lutz 1989). Accordingly, the fertility decrease after the baby boom was stronger from the children's perspective: while the average number of children per woman decreased by 0.5 between the 1935 and 1950 birth cohort, the children born by those women in average experienced the "loss" of almost one brother or sister.

The decomposition of demographic trends by municipality type-the ruralurban setting at age 15-reveals very different patterns of change. Women with a rural background display very high and stable low-order parity progression rates. Higher-order parity progression rates temporarily increased during the baby boom and sharply dropped afterwards. For women with an urban background, large families were uncommon and this applies already to earlier cohorts. The baby boom mainly led to a decline in childlessness and increased second-order parity progression rates. Following the baby boom, cohort fertility fell more rapidly in the rural category, resulting in diminishing rural-urban differentials (see Figure 4).

\section{Figure 4:}

Cohort fertility and parity progression rates by municipality type

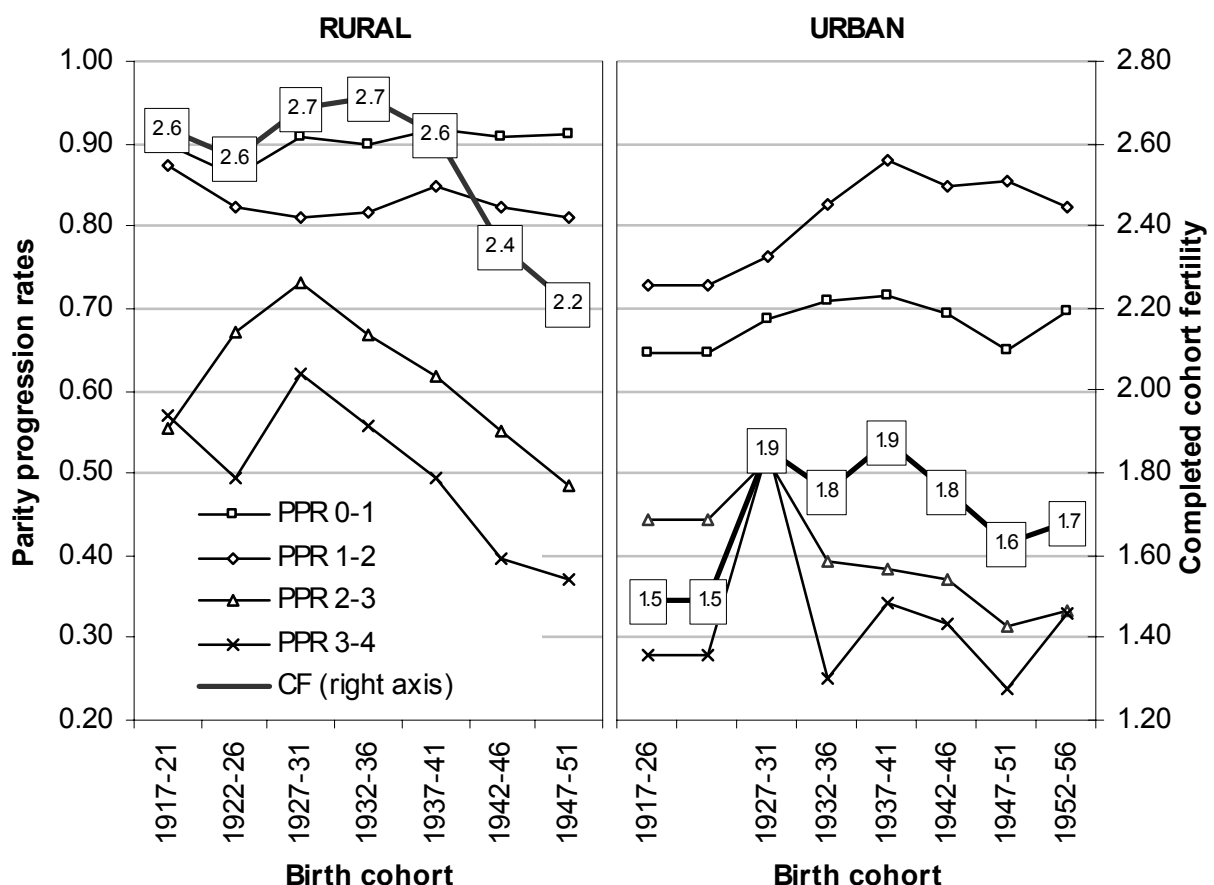

Source: Microcensus 1996; own calculations.

Note: The municipality type refers to the rural-urban setting in which a woman lived at age 15 . 
Rural-urban differentials in fertility levels are also reflected in different concentration ratios. In a more detailed analysis, we further distinguish women who-at age 15-lived in Vienna from those who lived in other urban municipalities and build an additional category for women who did not live in Austria as they have a very different pattern of change. Figure 5 displays the trajectories of average family size from women's, mothers' and children's perspectives, together with the concentration measures for the four municipality categories distinguished.

For women who lived in rural municipalities, childlessness remained at a constant and low level of around 10\% throughout the cohorts studied, even though the concentration of births declined, leading to an even faster reduction in the average family size from the children's perspective. Women who did not live in Austria when aged 15 approached almost exactly the rural values concerning all measures displayed in Figure 5 although the trajectories towards this pattern are very different, most notably the reduction in childlessness by half accompanied by decreasing family sizes. Both urban patterns are distinguished by lower fertility levels, higher concentration, and a reversal of concentration trends; the recent increase in concentration can therefore be identified as an entirely urban phenomenon. A comparison between Vienna and other urban municipalities reveals generally higher levels of childlessness and concentration in Vienna. By contrast to all other groups, no perceptible baby boom took place in Vienna.

\subsection{Fertility and Concentration Trends by Educational Attainment}

Besides the rural-urban differentials, there exist considerable educational differentials in fertility and concentration levels and trends. Cohort fertility levels exceeding the replacement level, as observed for the baby boom cohorts, were entirely triggered by the high fertility of women with the lowest of the eight different educational attainments distinguished in the census. Even in times of the fertility peak, with a CFR of almost 2.5 , no other educational group of females reached replacement-level fertility. As the share of women with only compulsory education decreased considerably over time and recently levelled off at around 17\% (Spielauer 2004a), the recent fertility decline can partly be attributed to composition effects. As can be seen in Figure 6 (which aggregates education levels to five categories), fertility fell in all groups but one: women graduated 
Figure 5:

Cohort fertility, average family size, and proportion of only children from a children's perspective, and concentration measures by municipality type

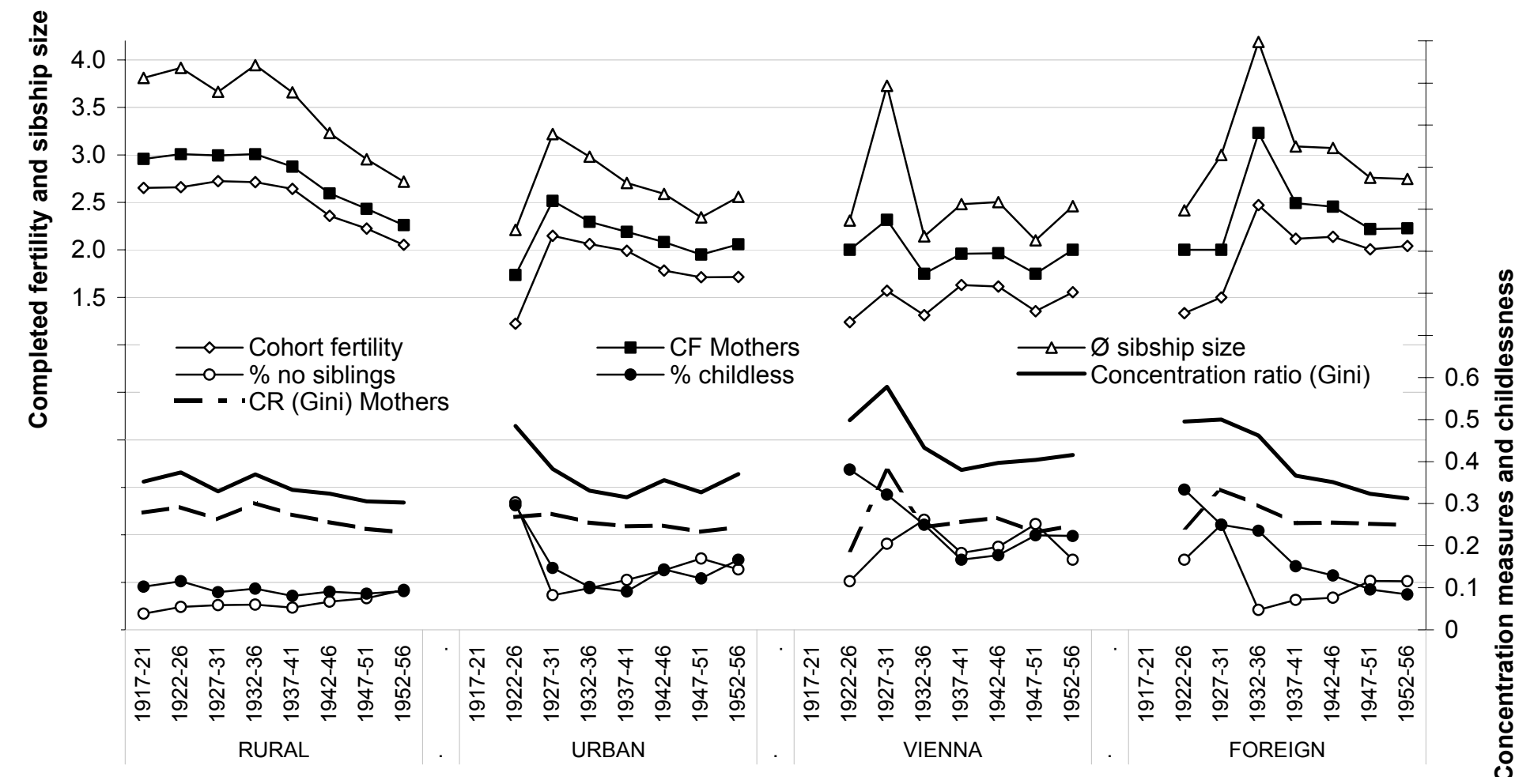

Source: Micro census 1996; own calculations.

Note: The municipality type refers to the setting in which a woman lived at age 15 . 
from academies ${ }^{8}$ (non-university tertiary education, which predominantly train teachers, educators, and social workers).

Fertility differentials by educational attainment are narrow when considering mothers only, especially for women with an education higher than compulsory and this highlights the role of childlessness as a determinant of heterogeneous cohort fertility levels. The two-child family became the dominant norm for mothers almost regardless of educational attainment; even university graduates born around 1960 with a cohort fertility level of only 1.35 children have an average family size of almost 2 children (if they do not stay childless).

\section{Figure 6:}

Cohort fertility of women and mothers by educational attainment

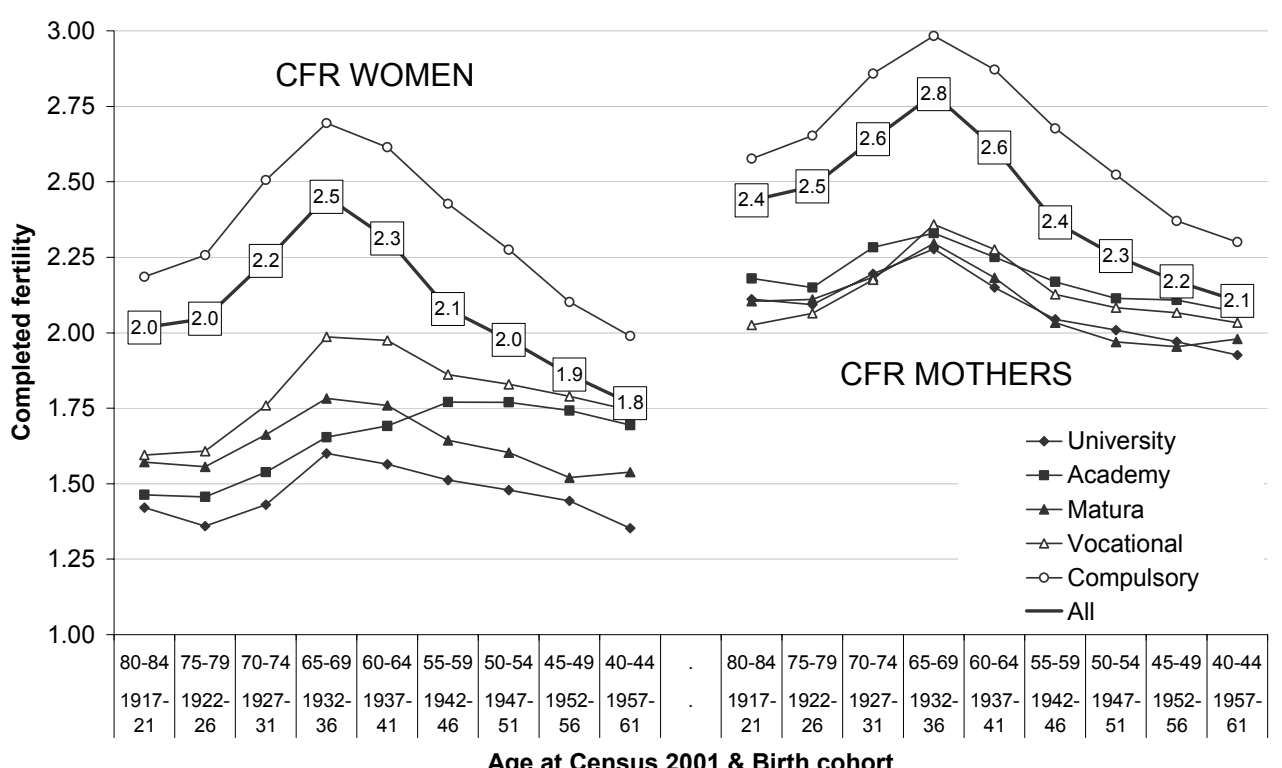

Source: Census 2001; own calculations.

Figure 7 displays the evolvement of average family sizes from women's, mothers' and children's perspectives, together with concentration measures for the five educational categories distinguished.

The trajectories of childlessness are the dominant source of fertility differentials and this is clearly reflected in the shape of the concentration ratios.

8 According to the 2001 census, $38 \%$ of the women with tertiary education (birth cohorts 1917 $61 ; 5,7 \%$ of this population has tertiary education) graduated from such academies. According to the pooled data of the 1996 and 2001 microcensuses for birth cohorts 1945-56 underlying Figure 8, two thirds of women who graduated from academies (and on whom information on their profession is available) report to be teachers. 
Figure 7:

Cohort fertility, average family size, and proportion of only children from a children's perspective, and concentration measures by educational attainment

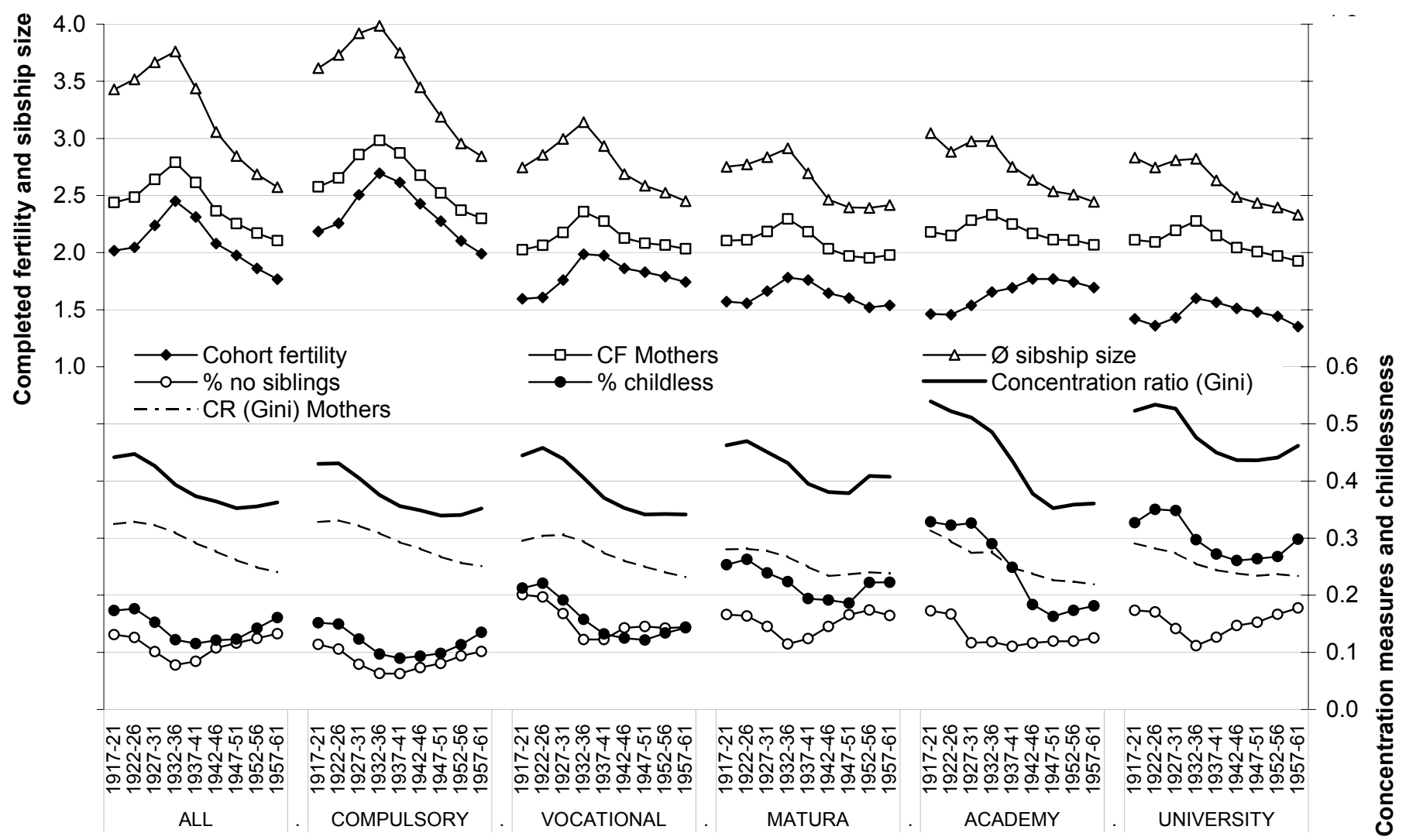

Source: Census 2001; own calculations. 
Given the generally decreasing levels of concentration concerning merely mothers, it is the only factor that leads to the recent increase of concentration within most educational groups. The most illustrative example of the difference between mothers' and children's average family sizes are the trajectories for graduates of academies: while overall fertility increased due to rapidly falling proportions of childlessness, the average sibship size from the children's perspective declined. From the same perspective, the influence of mothers' education on sibship size was always small except for children of mothers with compulsory education only. These children had on average one additional brother or sister during the baby boom. The difference, however, gradually diminished by half when looking at the cohort last studied. A remaining difference is the different proportion of only children. This proportion is highest for children of university graduates or mothers with a Matura diploma.

A comparison of concentration ratios by educational attainment reveals a clear ranking, with the highest concentration found for university graduates. Women who graduated from academies are an exception: they display a very different trajectory in that they move from the highest level of concentration to a relatively low level. A large proportion of academies are training teachers for primary and secondary non-academic schools. Historically, the teaching profession represented an occupational group with high levels of childlessness due to the high importance that religious schools and nuns used to play in the educational system.

\subsection{Additional Factors, Interaction, and Composition Effects}

The recent low levels of concentration and childlessness of graduates from academies raise the issue of the interaction between the profession and the educational level; we would expect that teachers are generally a lowconcentration group with low proportions of childlessness. As Figure 8 shows, however, the latter is not the case: university-trained teachers display considerably higher levels of concentration, even when teaching in the same type of schools (as shown in Spielauer (2004c), the same holds true for childlessness). A reason may be the very different study durations of these two educational tracks. Average study durations at universities are extremely long in Austria: 7.5 years for a master degree compared to 4 years of regular study, and 3 years of study at academies (Spielauer et al. 2003; Landler 1997). In general, Figure 8 reveals a wide dispersion of concentration by profession within educational categories whereas within professional categories, concentration frequently increases with education. 
Figure 8:

Concentration ratios by educational attainment and profession for female birth cohorts 1945-56; selected professional groups

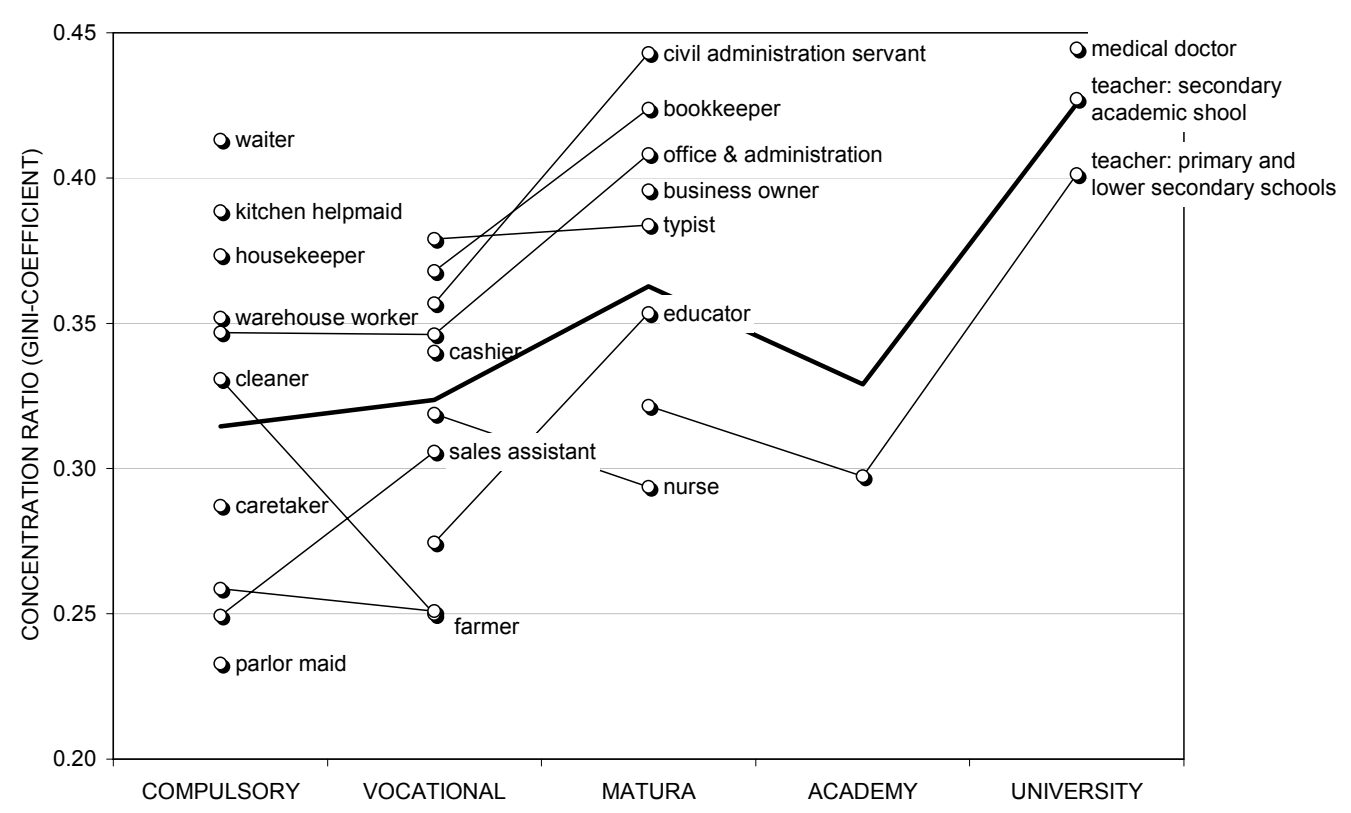

Source: Pooled data from the microcensuses 1996 and 2001.

An analysis of intergenerational mobility reveals that concentration is not only influenced by one's own educational level but also by the difference to parents' education. As shown in Figure 9, this effect is very strong in the upper and lower end of the educational spectrum. As to the latter, differences in concentration are entirely the result of different proportions of childlessness, which (like the probability of never marrying) is twice as high for women of compulsory education who have parents with higher education than for women whose mothers and fathers had compulsory education as well. $17 \%$ of female birth cohorts $1932-$ 56 with compulsory education $(\mathrm{n}=2644)$ belong to the downward-mobile group. Downward mobility to the lowest educational level might indicate also other disadvantages (e.g., health problems) and coincide with professions in which childlessness is high, such as for waiters (Figure 8). We find the reverse effect of upward-mobility for university graduates. When none of the parents had tertiary education, childlessness is $50 \%$ higher, but also the concentration of births among mothers increases. This can be interpreted as a selection effect due to a higher job orientation of upward-mobile women. Of the analysed university graduates of the birth cohorts $1932-56,59 \%$ (of $n=163$ ) belong to the upward-mobile group. 
Figure 9:

Cohort fertility, average family size, and proportion of only children from a children's perspective; concentration measures by educational attainment and intergenerational educational mobility; female birth cohorts 1932-56

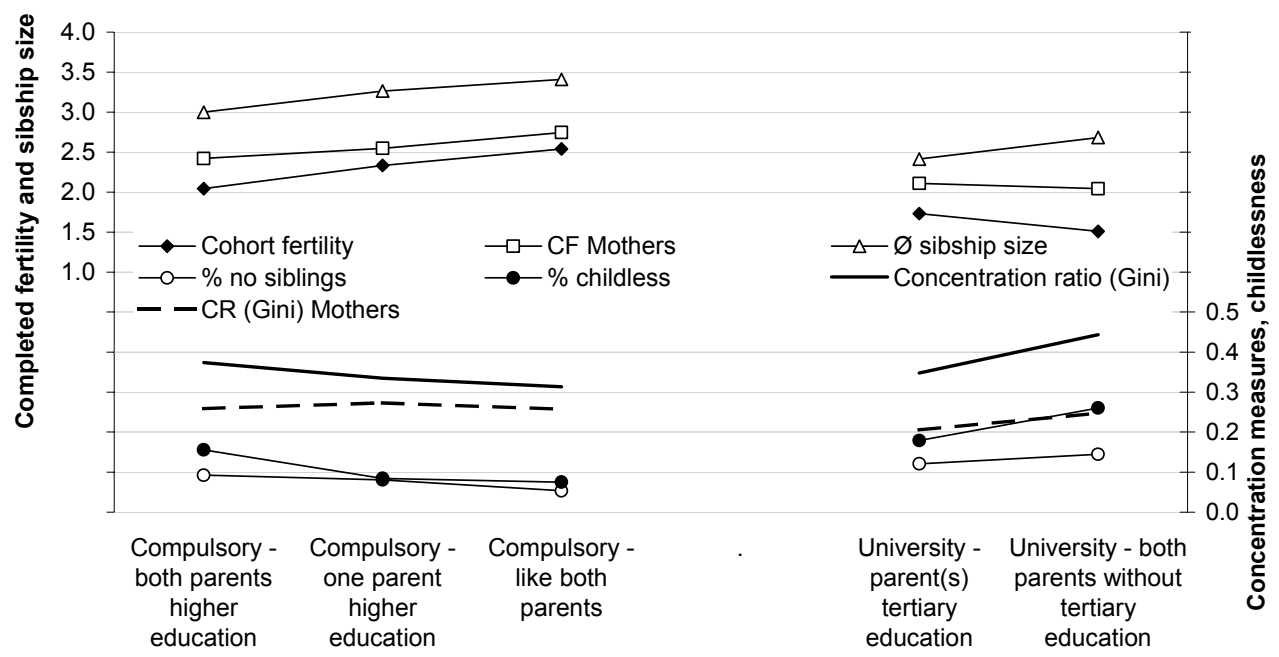

Source: Microcensus 1996; own calculations.

Given the strong impact of the urban-rural setting on the level and the trajectory of concentration over time (as discussed in Section 5.2) an analysis of possible interactions between municipality type and education would suggest itself. Unfortunately, the possibility for such an analysis is rather restricted due to the small sample size of the microcensus especially for higher educational categories. In Figure 10, we distinguish between six rural-urban-educational combinations of four 10-year birth cohorts. As expected, concentration decreased over time for women of the rural category, a decline that levelled off for women with higher education (Matura, academy or university). According to our previous analysis, the recent increase of concentration is an exclusively urban phenomenon. Interestingly, higher educated women with an urban background did not follow this pattern. With a constant and low level of cohort fertility-1.5 children per women - this group did not contribute to the baby boom. Also their concentration ratio remained almost constant over time.

We can expect strong composition effects due to the very different educational composition of the population by municipality type (see e.g., Spielauer et al. (2003) for an analysis for Austria). For instance, within the group of higher educated women, the proportion of females with an urban background is higher than for lower educated women - and vice versa - and this leads to a higher concentration of births in cities, partly due to the different educational composition of the population and trajectories in higher educational categories 
Figure 10:

Cohort fertility, average family size, and proportion of only children from a children's perspective; concentration measures by educational attainment and municipality type

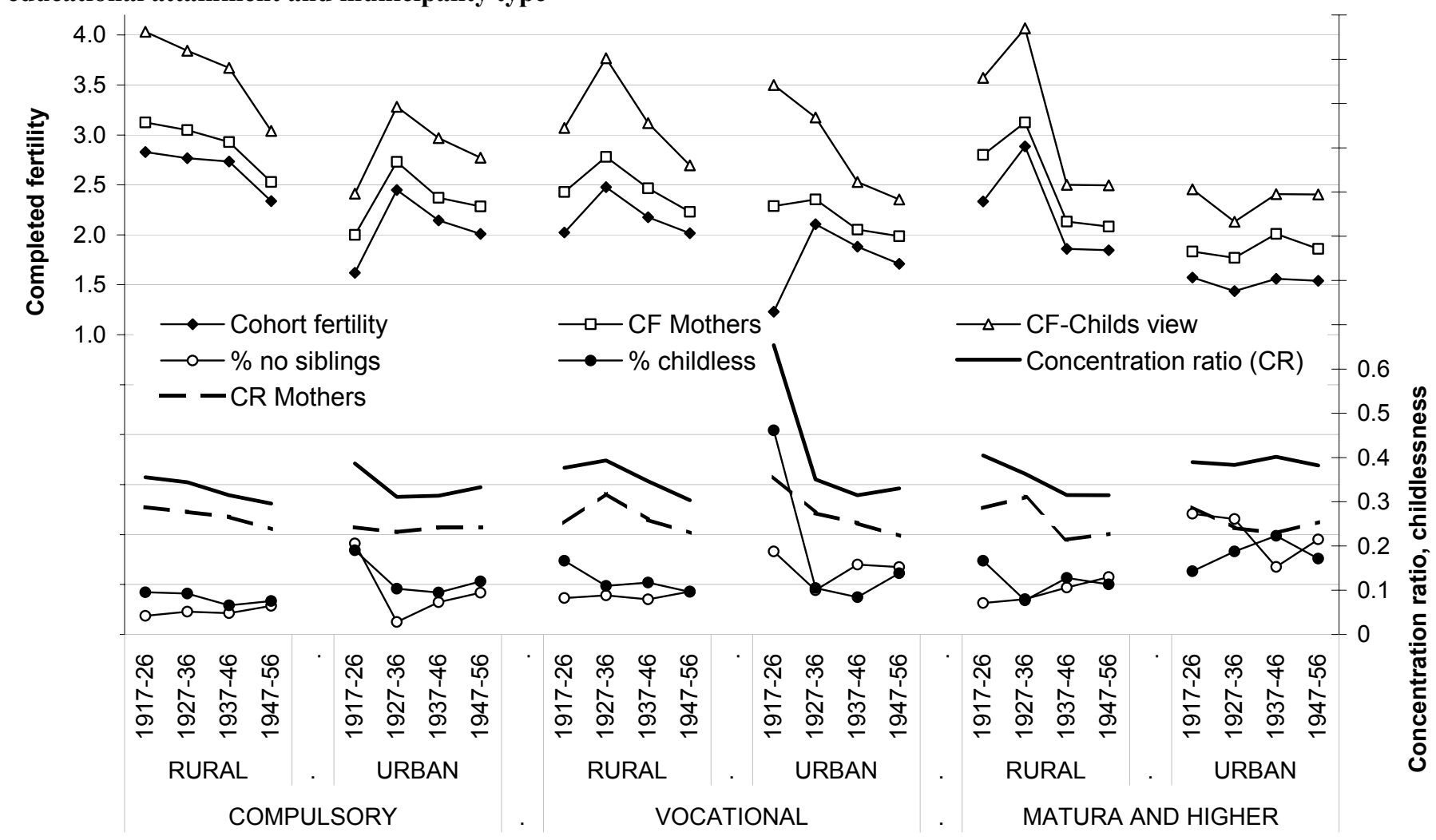

Source: Micro census 1996; own calculations.

Note: The municipality type refers to the rural-urban setting in which a woman lived at age 15 . 


\section{Figure 11:}

Composition effects of different educational compositions by municipality type and of different municipality compositions by educational attainment
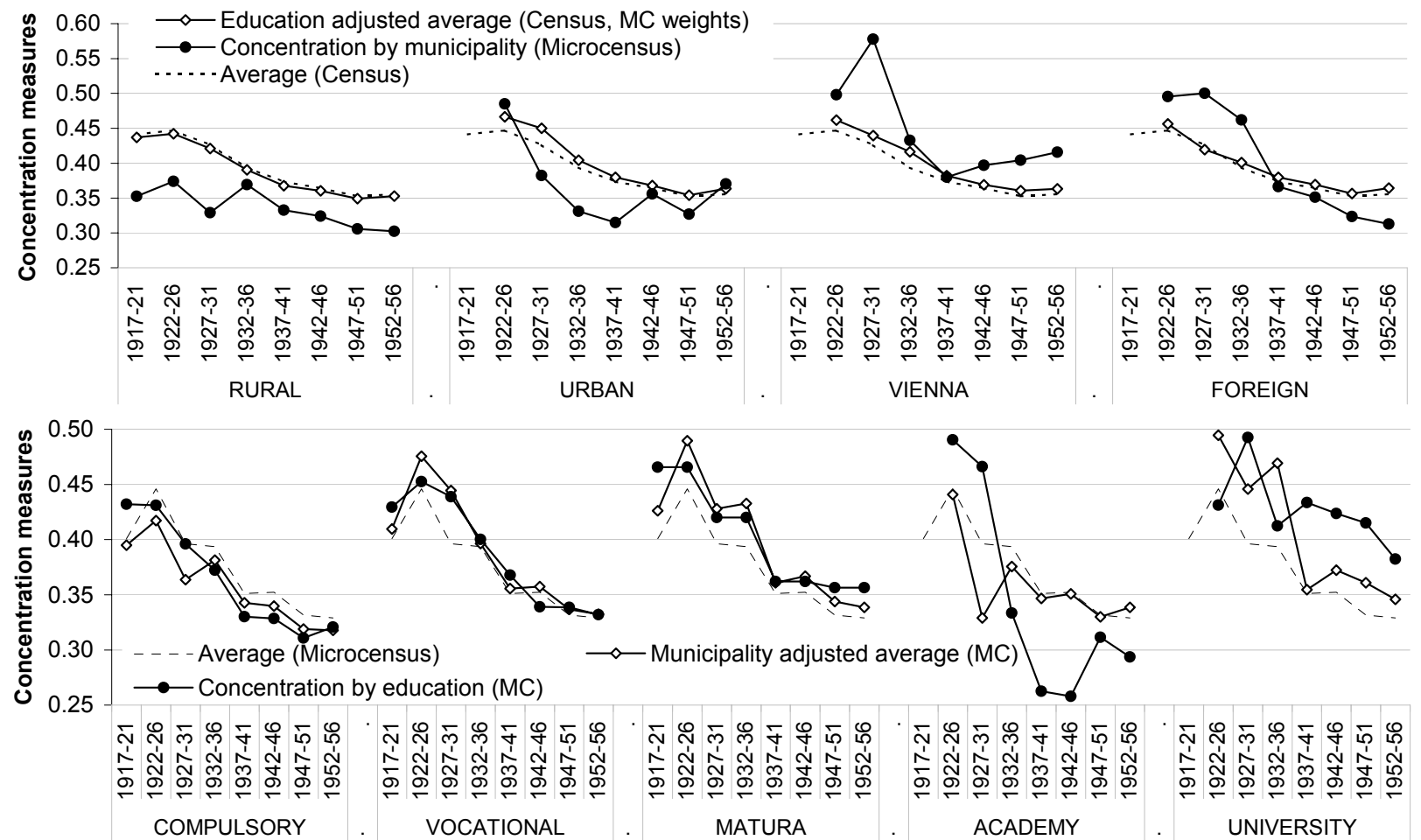

Source: Census 2001, Micro census 1996; own calculations.

Note: Averages refer to population averages. The average values calculated from micro census data only include cases with complete information on municipality type and education and therefore slightly differ from the average values presented in Table 1. The adjusted averages were calculated from re-weighted populations that represent the educational and municipality composition found within the group, respectively. 
that are more "urban". One way of exploring the contribution of composition effects to the different trajectories of concentration is to adjust the average concentration trend for the different educational compositions within each municipality type (or vice versa) by means of re-weighting the population from which the concentration ratio is calculated. As shown in Figure 11, the educational composition does not play an important role in explaining differences in the concentration of reproduction between urban and rural settings. By contrast, the different population compositions by municipality type within the various educational categories play a substantial role in the concentration differentials by educational attainment.

From Figure 11 we can conclude that educational differences of concentration are rather small for women with non-tertiary education when controlling for the municipality background. The very different trajectory for graduates of academies, by contrast, persists, as does the generally higher concentration of reproduction within the group of university graduates although composition effects are strong for this group as well.

\section{Summary and Conclusions}

In the European context, Austria is among the countries with the highest concentration of reproduction, a position it held for all birth cohorts 1917-61 studied in this paper. As in most Western countries, the concentration started to decline with the onset of the baby boom and continued to decrease in the period following the boom as the two-child norm gained dominance and rural-urban and educational differentials partly narrowed. Therefore, in contrast to earlier experiences, fertility and concentration moved in the same direction after the baby boom, leading to a faster demographic change from the children's perspective. While fertility differentials by educational attainment are still high, different levels of concentration within educational groups lead to rather uniform family sizes from this perspective. Besides educational differentials, we found very different patterns of demographic change by municipality type. Controlling for this effect, educational differentials become small for lower educational groups. For women with tertiary education, fertility and concentration follow very different trajectories: university graduates have the lowest fertility and the highest concentration of reproduction, mainly due to their high level of childlessness. For graduates from academies, by contrast, fertility increased until the 1950 cohort and concentration as well as childlessness reached comparably low levels. As academies predominantly train teachers, we studied the interactions between professions and educational attainment. Concentration (and childlessness) is much higher for teachers trained at universities, even if teaching at the same type of schools. This can be interpreted as evidence that the long average study duration at Austrian universities is one of the reasons for the very low fertility of university 
graduates. Concentration and childlessness among university graduates is especially high for women whose parents have a lower educational attainment, which indicates a selection effect, e.g., a higher job orientation of upward-mobile women. We find the opposite effect at the lower end of the educational spectrum, i.e., high childlessness and concentration together with lower fertility of women who did not reach the same educational level as their parents.

As in most other European countries, the concentration of reproduction has grown in the most recent birth cohorts due to rising childlessness. In Austria, this increase is still very small for the studied cohorts and an entirely urban phenomenon. Due to the ongoing rise in childlessness, we can assume a stronger growth of concentration for the cohorts to follow. This development will have socio-demographic, economic, and policy implications as it affects the future socialisation of children, income distribution, and demand structures, e.g., for formal care services.

\section{Acknowledgements}

I am thankful to Vladimir Shkolnikov and René Houle for their comments and to Susann Backer for careful language editing of this contribution.

\section{References}

BIB. 2000. Bevölkerung: Fakten - Trends - Ursachen - Erwartungen. Wiesbaden: Bundesinstitut für Bevölkerungsforschung.

Eurostat. 2002. New Cronos database. Theme 3: Population and social conditions.

Frejka, T. and J.-P. Sardon. 2003. "Fertility in Austria: Past, present and the near future." Working Paper 02/2003, Vienna: Vienna Institute of Demography.

Frejka, T. and J.-P. Sardon. 2004. "Fertility in Austria: Past, present and the near future." Vienna Yearbook of Population Research 2004: 35-56. Vienna: Vienna Institute of Demography.

Frejka, T., W. W. Kingkade, G. Calot, and J.-P. Sardon. 2001. "Cohort childlessness and parity in low-fertility countries." Presented at: European Population Conference 2001, Helsinki, Finland 7-9 June 2001.

Goodwin, D. G. and J. W. Vaupel. 1985. "Curves and have-statistics for ecological analysis of diversity. Part III: Comparison of measures of diversity." Working Paper WP-85-91, Laxenburg: International Institute for Applied System Analysis.

Hanika, A. 2003. „Volkszählung 2001: Paritäts-Fertilitätstafeln.“ Statistische Nachrichten 58: 90-96, Vienna: Statistics Austria.

Heuser, R. L. 1976. Fertility tables for birth cohorts by color. U. S. Department of Health, Education, and Welfare. DHEW Publication No. (HRA)76-1152. 
Hoem, J. M., G. R. Neyer, and G. Andersson. 2005. "Childlessness and educational attainment among Swedish women born in 1955-59". MPIDR Working Paper WP2005-014. Available at:

$<<$ http://www.demogr.mpg.de/Papers/Working/wp-2005-014.pdf $>>$.

Kreyenfeld, M. 2002. "Parity specific birth rates for Western Germany - An attempt to combine survey data and vital statistics." Zeitschrift für Bevölkerungswissenschaft, 273: 327-357.

Landler, F. 1997. Das österreichische Bildungswesen in Zahlen - Analyse und Computersimulation des Schulsystems und der Qualifikationsstruktur der Bevölkerung. Vienna: WUV-Universitätsverlag.

Lutz, W. 1989. Distributional Aspects of Human Fertility. A Global Comparative Study. Academic Press, Harcourt Brace Jovanovich Publishers, London

Lutz, W. and J. W. Vaupel. 1987. "The division of labor for society's reproduction: on the concentration of childbearing and rearing in Austria." Österreichische Zeitschrift für Statistik und Informatik 171 (2): 81-95.

Murphy, M. 1999. "Is the relationship between fertility of parents and children really weak?" Social Biology, 46, 122-145.

Nave-Herz, R. 2002. Familie heute Wandel der Familienstrukturen und Folgen für die Erziehung. Second (revised) edition, Primus.

Podrazka A. 1989. "Types of the demographic transition in the countries of Europe." Studia Demograficzne 98: 49-73.

Shkolnikov, V. M., E. M. Andreev, R. Houle and J. W. Vaupel. 2004. "The concentration of reproduction in cohorts of US and European women." MPIDR Working Paper WP2004-027. Rostock: Max Planck Institute of Demographic Research.

Spielauer, M. 2004a. "Intergenerational educational transmission within families: an analysis and microsimulation projection for Austria." Vienna Yearbook of Population Research 2004.

Spielauer, M. 2004b. "Les politiques familiales en Europa: une typologie." Population y Avenir, No. 666, January, February 2004.

Spielauer, M. 2004c. "Childlessness and the concentration of reproduction in Austria." MPIDR Working Paper WP-2004-028. Rostock: Max Planck Institute for Demographic Research.

Spielauer, M., F. Schwarz, K. Städtner, and K. Schmid. 2003. Family and education: intergenerational educational transmission within families and the influence of education on partner choice and fertility; analysis and microsimulation projection for Austria. Schriftenreihe 11, Vienna: Austrian Institute for Family Studies.

Vaupel, J. W. and D. G. Goodwin. 1987. "The concentration of reproduction among US women, 1917-80." Population and Development Review 134: 723-730. 